\title{
Ensino da Arte na escola pública e aspectos da política educacional: contexto e perspectivas
}

— Karina Barra Gomes*

Sonia Martins de Almeida Nogueira**

\section{Resumo}

Este artigo procura ampliar constatações e considerações que abrangem o ensino da Arte na escola pública e aspectos da política educacional. Nossa inquietação, quanto ao percurso do ensino artístico no país e a sua realidade nos dias atuais, levounos a contextualizá-lo a aspectos da políitica educacional, associando o ensino a questões que incitam a conscientização dos professores de Arte, sua atuação e o envolvimento com a prática pedagógica diante das condições educacionais que nos permite viver a política educacional marcada pela globalização e pela pós-modernidade.

Palavras-chave: Ensino de Arte. Política educacional. Formação de professores. Globalização.

\section{Teaching of art at public schools and educational politics aspects: contexts and perspectives Abstract}

This article aims to amplity the evidences and considerations that deal with the teaching of Art in public schools and also with some public politics aspects. Our worries about the teaching of Art path in this country and its reality nowadays has driven us to conceptualize it with some educational politics aspects, associating the teaching of Art to subjects that stir teachers' awareness, their performance and their involvement in pedagogic practices in the pedagogic conditions, that allowed us to live the pedagogic politics which are marked by globalization and postmodernism. Keywords: Teaching of Art. Educational politics. Teacher's formation.

Globalization.

\section{Enseñanza del arte en la escuela pública y aspectos de la política educacional: contexto y perspectivas Resumen}

Este artículo busca ampliar constataciones y consideraciones que abarcan la enseñanza del Arte en la escuela pública y aspectos de la política educacional.

\footnotetext{
* Mestre em Políticas Sociais, Universidade Estadual do Norte Fluminense Darcy Ribeiro (UENF). E-mail: gomes.karina@gmail.com

** Doutora em Educação, Universidade Federal do Rio de Janeiro; Professora da UENF. E- mail: smanogueira@infolink.com.br
} 
Nuestra inquietud con relación al curso de la enseñanza artística en el país y su realidad en los días actuales nos llevó a contextualizarla a aspectos de la política educacional, asociando la enseñanza a cuestiones que incitan la concientización de los profesores del Arte, su actuación y el envolvimiento con la práctica pedagógica frente a las condiciones educacionales que nos permite vivir la política educacional, marcada por la globalización y por la pos-modernidad. Palabras clave: Enseñanza del Arte. Política Educacional. Formación de profesores. Globalización.

\section{Introdução: o cenário do ensino de Artes no século $X X$ e primeiros anos do século XXI}

Shiroma, Moraes e Evangelista (2002) nos chamam a atenção para o caráter histórico da educação na política brasileira até meados de 1970, quando se direcionava para o fortalecimento do Estado. Políticas públicas eram implementadas na educação, revestidas de uma "forte motivação centralizadora" e associadas a discursos de construção nacional, em que valores que engrandecessem a "nação forte" fossem aplicados às políticas educacionais.

Na primeira metade do século XX as disciplinas Desenho, Trabalhos Manuais, Música e Canto Orfeônico faziam parte dos programas das escolas primárias e secundárias, com uma visão de ensino baseada na escola tradicional (BRASIL, 1997). Assim, encontramos no ensino de música, por meio do Canto Orfeônico, o aspecto de caráter nacional na formação da população que vivenciou esse período da história da educação. Mas, os pressupostos da escola nova também contribuíram, nos anos 30, para novas propostas no ensino da Arte.

Entre os anos 20 e 70, as escolas brasileiras viveram experiências diversas no ensino da Arte, mas nos anos 30 e 40 dominou o Canto Orfeônico, projeto elaborado pelo compositor Heitor Villa-Lobos, que pretendia difundir a linguagem musical de maneira sistemática, juntamente com princípios de civismo e coletividade, condizentes com o pensamento político da época (BRASIL, 1997).

Nesse percurso histórico, a Lei nº 4.024 (BRASIL, 1961) - Lei de Diretrizes e Bases Educação Nacional - LDBN, de 1961, instituiu a Educação Musical. Seus dispositivos estabeleceram novas diretrizes para a política educacional e definiram orientações que redesenharam a proposta curricular da legislação anterior, mas Romanelli (1997, p. 181) afirma que, "na prática, as escolas acabaram compondo o seu currículo de acordo com os recursos materiais e humanos de que já dispunham, ou seja, continuaram mantendo o mesmo currículo de antes", apesar de considerarem que "a possibilidade de os Estados e os estabelecimentos anexarem disciplinas optativas ao currículo mínimo" ter sido um avanço em matéria de educação.

Na década de 60, o país enfrentava o regime militar como modelo de sua ordenação política e apresentou-se um novo cenário, diferente do atual. Naquele momento, pensava-se em adequar o ensino ao modelo do desenvolvimento econômico da época, em que a tendência a uma Pedagogia Tecnicista, segundo Fusari e Ferraz 
(2001), passou a atender o mundo tecnológico e a sociedade industrial em expansão. Havia uma busca do Estado voltada para o investimento num modelo de educação que formasse mão-de-obra qualificada e que viesse a favorecer o processo de importação tecnológica. Quanto a isso, Shiroma, Moraes e Evangelista (2002, p. 36) afirmam que o "educador e educando haviam-se transformado em capital humano", para a produção de lucros individuais e sociais, e Romanelli (1997, p. 196) argumenta que, a partir dos anos 60, o governo percebeu "a necessidade de se adotarem, em definitivo, as medidas para adequar o sistema educacional ao modelo do desenvolvimento econômico que então se intensificava no Brasil".

Com a reforma de 1971, a Lei n 5.692 (BRASIL, 1971) incluiu a Arte no currículo escolar com o título de Educação Artística, porém era considerada apenas uma "atividade educativa" e não uma disciplina: "Será obrigatória a inclusão de Educação Moral e Cívica, Educação Física, Educação Artística e Programas de Saúde nos currículos plenos dos estabelecimentos de $1^{\circ}$ e $2^{\circ}$ graus [...]". Admitimos que a introdução da Educação Artística no currículo escolar por esta LDBN foi um avanço, tanto pelo aspecto de sustentação legal para esta prática, quanto por ter sido considerada importante na formação dos indivíduos. Porém, essa alteração criou questões novas a serem enfrentadas, principalmente para os professores de cada uma das disciplinas artísticas.

Após esta Lei, os professores de Desenho, Música, Trabalhos Manuais, Canto Coral e Artes Aplicadas, que utilizavam para as aulas os conhecimentos específicos de suas linguagens, passaram a ver esses saberes transformados em "atividades artísticas", o que fica claro na análise do Parecer n 540/77 (CONSELHO FEDERAL DE EDUCAÇÃO, 1977): "não é uma matéria, mas uma área bastante generosa e sem contornos fixos, flutuando ao sabor das tendências e dos interesses". Segundo Fusari e Ferraz (2001), os professores das escolas públicas encontraram dificuldades em apreender métodos de ensino nas salas de aula, resultando numa prática pouco ou nada fundamentada, necessitada de aprofundamentos teórico-metodológicos. Neste sentido, as autoras (FUSARI; FERRAZ, 2001, p. 43) afirmam que:

Dentre os problemas apresentados no ensino artístico, após a Lei 5692/71, encontram-se aqueles referentes aos conhecimentos básicos de arte e métodos para apreendê-los durante as aulas, sobretudo nas escolas públicas. $\bigcirc$ que se tem constatado é uma prática diluída, [...], na qual métodos e conteúdos de tendência tradicional e novista se misturam, sem grandes preocupações, com o que seria melhor para o ensino de Arte.

Em 1996, a Lei n 9.394 (BRASIL, 1996, Art. 26, § 2) estabeleceu que o ensino da Arte constituísse "componente curricular obrigatório, nos diversos níveis da educação básica, de forma a promover o desenvolvimento cultural dos alunos". Apesar do "avanço" desta Lei, a escola e o sistema educativo atual têm enfrentado desafios que transcendem a dimensão estrutural do currículo e a dinâmica das metodologias de ensino. As políticas educacionais da atualidade necessitam adequar-se às questões sociais que estão refletidas na escola pública, como o desemprego, a violência e a marginalização, que se acentuaram como possíveis reflexos da globalização da economia, da política e da cultura. 
Os problemas atuais da sociedade, dos bairros e da comunidade, que adentram pelo portão das escolas, influenciam o modo pelo qual as políticas públicas são recebidas e postas em ação no ambiente escolar. Talvez seja importante estudar as políticas adotadas em diferentes períodos da educação, para que seja possível identificar as contribuições que, ao ensino atual, cabe oferecer à grande maioria das escolas públicas, que enfrentam dificuldades para colocar em prática as diretrizes e ações políticas estabelecidas no plano de governo, à luz da legislação.

Visto que o artigo 10 da Lei n. 9.394 (BRASIL, 1996) aponta que um dos deveres do Estado é "elaborar e executar políticas e planos educacionais, em consonância com as diretrizes e planos nacionais de educação, integrando e coordenando as suas ações e as dos seus Municípios", notamos que é responsabilidade do Estado pôr em prática as diretrizes das políticas educacionais que atendam de forma eficaz às necessidades da educação.

Magalhães (2002, p. 164-165) expressa a sua preocupação com o ensino da Arte no Brasil, ao afirmar que:

Muitas são as questões que envolvem os motivos de tantas fragilidades conceituais e metodológicas no campo do ensino-aprendizagem em Arte: a inexistência de recursos humanos, a inexperiência pedagógica e a conseqüente falta de questionamentos, são as causas apontadas pelo Parecer n ${ }^{\circ}$ 440/77, [...]. Faz-se necessário repensar o papel da Arte na educação escolar frente às reformas curriculares advindas da LDB atual (Lei 9.394/96) e a conseqüente divulgação dos Parâmetros Curriculares Nacionais-Arte, elaborados pelo MEC [...] que ratificam a presença das diversas linguagens artísticas nas escolas - música, teatro, dança e artes visuais e a Proposta de Diretrizes Curriculares sistematizada pela Comissão de Especialistas de Ensino de Artes Visuais da SESu/MEC.

Em vista disso, urge a necessidade de re-significar os currículos escolares de maneira geral, principalmente, a formação do professor de Arte frente à rapidez das mudanças deste final de milênio. Como os cursos de Licenciatura em Artes estão preparando o professor para um posicionamento crítico frente às novas perspectivas teórico-metodológicas subjacentes nos documentos propostos pelo MEC?

Esta argumentação da autora nos permite refletir sobre a qualidade do ensino de Educação Artística apresentada atualmente no ensino fundamental e médio das escolas públicas. $\bigcirc$ ensino de hoje tem correspondido aos critérios estabelecidos pelas propostas da política atual? As políticas de orientação curricular em Artes são postas em ação e bem recebidas pelos professores? E a questão da formação desses profissionais?

Torna-se importante destacarmos que a Lei $n^{\circ}$. 9.394 foi alterada pela Lei $n^{\circ}$. 2.732 de 2008 (BRASIL, 2008), aprovada em 21 de maio deste mesmo ano, e que dispõe sobre a obrigatoriedade do ensino da Música na educação básica. $\bigcirc$ Artigo 26 da Lei de 20 de dezembro de 1996 (BRASIL, 1996) passa a vigorar acrescido dos seguintes parágrafos: 
$\S 6^{\circ}$ A música deverá ser conteúdo obrigatório, mas não exclusivo, do componente curricular de que trata o $\S 2^{\circ}$.

$\S 7^{\circ} \bigcirc$ ensino da música será ministrado por professores com formação específica na área.

Vale ressaltar que a Lei também esclarece a respeito do sistema de ensino, que terá três anos para adaptar-se a essa nova exigência legal, tendo em vista a organização dos novos conteúdos a serem trabalhados na disciplina.

A verdade é que a Arte, de uma forma geral, não tem sido valorizada nas escolas como disciplina de importância dentro do processo pedagógico, o que se reflete na contratação de profissionais não ou pouco qualificados, e num certo menosprezo da Arte em relação às outras disciplinas mais tradicionais. Esperamos que, por meio da valorização da música como prática pedagógica em todos os níveis da educação básica, possamos presenciar o despertar de uma cultura democrática em que valores como diversidade, sensibilidade e cidadania sejam postos em evidência.

\section{Dilemas e ações nos anos 1990 e início dos anos 2000: breve abordagem}

Os Parâmetros Curriculares Nacionais - PCNs (BRASIL, 1997) são propostas do Ministério da Educação e do Desporto (MEC), datadas de 1997, 1998 e 1999, para a abordagem curricular da educação básica, com o objetivo de serem um referencial comum para a educação de todos os estados do Brasil. Assumiram a feição de política pública ao estabelecerem uma meta educacional para a qual devem convergir as ações políticas do MEC.

Ao orientar os professores que trabalham com Arte, o PCN (BRASIL, 1997) apresenta direções, caminhos, conteúdos, linguagens e critérios de avaliação a fim de expandir as possibilidades para os profissionais de Educação Artística. Por certo, os PCNs, de uma maneira geral, não exercem mais o mesmo impacto que já exerceram no final dos anos 90 , bem como nos primeiros anos do século XXI da educação básica, pois foram elaborados no governo Fernando Henrique Cardoso. É admissível que ainda mantenham orientações que sejam válidas e observadas; contudo, as orientações do Plano de Desenvolvimento da Educação - PDE vão, progressivamente, sendo acolhidas como novas diretrizes para a educação, apesar de não terem sido implantadas ainda todas as diretrizes da política educacional.

Ainda fazendo o uso dos PCNs, muitos professores têm tido dificuldades em aplicar as sugestões apresentadas por eles, de forma que também se torna questionador o papel destes como diretriz política eficiente nos dias atuais. Algumas questões reflexivas nos levam a indagar também a respeito da formação desses professores e seu envolvimento com a qualificação docente, pois a melhoria da qualidade do ensino requer maior atenção para a implementação de políticas públicas de formação inicial e continuada dos profissionais de educação (BRASIL, 2001). 
Considerando-se os resultados ainda pouco significativos no desenvolvimento da qualidade do ensino público, segundo índices nacionais e internacionais, as políticas públicas de educação, especialmente as de orientação curricular, deveriam dar maior ênfase, segundo acreditamos, à realidade escolar, o que acarretaria os menores efeitos perversos possíveis. Notamos que há um esgotamento do paradigma que, historicamente, fundamenta as políticas de reforma curricular.

De acordo com Almeida (2003, p. 75), por volta da década de 80, novas abordagens foram introduzidas no ensino da Arte no Brasil. A imagem' ganhou um lugar de destaque na sala de aula, o que representa uma das tendências da Arte contemporânea e uma novidade para o ensino da época. As imagens produzidas tanto pela cultura artística (pintores, escultores) como as produzidas pela mídia (propaganda de TV e publicitária gráfica, clip musical, internet) passaram a ser utilizadas pelos professores e alunos da educação básica.

O uso de diferentes imagens possibilitou aos professores maiores opções de conteúdos a serem explorados com os alunos, diversificando as possíveis formas de aprendizagem. As imagens passaram a ser valorizadas entre os educadores comprometidos com o desenvolvimento estético e artístico no ensino de Artes: "O professor decide quais imagens farão parte do repertório merecedor da apreciação dos seus alunos" (ALMEIDA, 2003, p. 73).

A partir de então, os docentes deveriam estar sempre em contato com a produção de imagens do seu tempo e atentos àquelas que eram produzidas pelos alunos em sala através de desenhos e pinturas. $O$ resgate da cultura da imagem se tornou necessário, o que passou a ser visto pelos estudiosos e pesquisadores como fator relevante para a formação do aluno.

Almeida (2003, p. 75) ainda discute a influência que a mediação das tecnologias tem provocado nas formas de pensar e expressar a Arte e como o artista sente a necessidade de buscar, em outras áreas do conhecimento, idéias que se possam somar as suas:

[...] o artista contemporâneo atento ao desenvolvimento tecnológico e científico vai incorporando novas ferramentas, que são meios diferentes de trabalho, buscando nas diversas áreas do conhecimento um compartilhar de idéias.

Nos últimos trinta anos, as tecnologias adentraram todas as esferas da vida humana. A educação se tornou um dos alvos desse processo da inserção das novas tecnologias na dinâmica do seu cotidiano. O impacto dos meios tecnológicos sobre a criação artística vem produzindo novas formas de expressão ao longo da história das Artes. A fotografia, o cinema e o vídeo encontraram suas próprias formas de expressão, além de possibilitarem a junção da narrativa, do

\footnotetext{
${ }^{1}$ Imagem se refere às obras de arte produzidas por meio artesanal e mecânico (pintura, desenho, gravura, escultura) ou mesmo às que são produzidas pela mídia (cinema, televisão, vídeo, internet), fotografia e às sintéticas, que são produzidas pelo computador.
} 
teatro e mais o uso dos recursos tecnológicos que a indústria trouxe à existência. A música passou a sofrer, já no final dos anos 40 e início dos anos 50, os impactos das técnicas de reprodução tanto na forma de expressão, como na produção em massa e na veiculação ${ }^{2}$.

A utilização do computador em sala de aula "revolucionou" a educação e a maneira pela qual o aluno se relaciona com os conteúdos que the são apresentados. Esta prática não propicia unicamente uma mudança objetiva e uma nova maneira de realizar tarefas, mas ultrapassou sua dimensão de utilidade, gerando uma nova forma de relação do aluno com a escrita, uma nova forma de comunicação, de organização do pensamento e uma nova percepção do tempo e do espaço. Segundo Pires (2003, p. 63):

[...] tais transformações afetam tanto as crianças que têm um computador em seu quarto, quanto àquelas que nunca chegaram a utilizá-lo. Trata-se de experiências diferenciadas que, no entanto, inscrevem-se num contexto compartilhado, na medida em que a existência do computador se impõe e marca a realidade [...].

grande desafio da educação através da Arte encontra-se no fato de ela deixar de ser apenas mais uma disciplina do currículo escolar e se tornar "algo incorporado à vida do sujeito, que o faça buscar a presença da arte como uma necessidade e um prazer, como fruição ou como produção, porque em ambas a arte promove a experiência criadora da sensibilização" (MEIRA, 2003, p. 131).

Para que tal objetivo seja alcançado, é necessário que os educadores desenvolvam uma consciência política em que estejam integradas arte, educação e cultura, juntamente com uma proposta que dê prioridade às necessidades da classe popular que freqüenta as escolas públicas. $\bigcirc$ professor tem um papel fundamental na condução de suas propostas, devendo estar atento às carências que os alunos da escola pública apresentam nos conteúdos de Arte.

Cada escola inserida numa determinada comunidade possui sua própria realidade social que difere das realidades de outras escolas localizadas em comunidades, bairros ou cidades diferentes. Este fato interfere diretamente na maneira pela qual o docente irá selecionar os conteúdos a serem aplicados, pois isso dependerá não somente dos recursos de que a escola possa dispor, mas também dos alunos para quem se dirige a ação pedagógica. Jesus (2002, p. 111) confirma esta idéia: "Faz-se necessário trabalhar com profissionais da educação de maneira que eles, sendo capazes de compreender suas práticas e refletir sobre elas, sejam também capazes de transformar as suas lógicas de ensino".

Entendemos que seja importante para os professores dessa disciplina que haja uma compreensão histórica do ensino da Arte nas escolas públicas do Município, uma

2 O PDE confirma a importância dessa nova adequação tecnológica ao ensino, propondo um Debate sobre a inserção das tecnologias nas escolas, tema que é tratado como uma de suas prioridades (BRASIL, 2007). Entre os dias 18 e 20 de junho de 2008 houve um encontro em Fortaleza para levantar essa discussão e a previsão é para a realização, neste mesmo ano, de quatro reuniões em que o tema seja abordado. 
análise das políticas que já foram adotadas em períodos passados a partir da legislação anterior e das políticas atuais, com o objetivo de auxiliá-los na prática pedagógica.

Todo o caminho percorrido pelo ensino das Artes no Brasil, segundo Barbosa (1999), vai desde o ensino jesuítico, com uma valorização exacerbada das artes literárias e com a inclusão das aulas de Desenho no currículo, após a reforma educacional executada pelo Marquês de Pombal. $\bigcirc$ ensino de hoje é marcado pela utilização de tecnologias avançadas como a informática, nas aulas de Arte, principalmente quando estão vinculadas às linguagens visuais.

Assim, durante a trajetória do ensino até os dias atuais, foram necessárias várias alterações na prática escolar, até mesmo na legislação. Portanto, resta identificarmos se o ensino atual tem correspondido ao que deve ser, tomando como referência as orientações trazidas pelo PCN (BRASIL, 1997) e o direcionamento que os professores dão aos conteúdos que apresentam em sala de aula. $\bigcirc$ Plano de Desenvolvimento da Educação (BRASIL, 2007) associa as conquistas alcançadas na qualidade da educação, desde o seu lançamento, aos professores que possuem formação que os capacite a exercer o magistério.

As políticas que incentivam o ensino de Arte devem contribuir para que a prática pedagógica atenda à necessidade de aprendizagem do aluno da escola pública dentro do seu contexto social, cultural e econômico. As políticas não podem mais ficar distantes da realidade dessas escolas e dos seus alunos, uma vez que se questiona a qualidade do ensino artístico em muitas escolas por lhes faltarem infra-estrutura, material de apoio e professores qualificados. As políticas de incentivo ao ensino necessitam acompanhar as modificações na educação e dar a sua contribuição. Os professores precisam estar sempre se atualizando, pois, sem adquirir um conhecimento básico em Arte, torna-se impossível contribuir para que uma consciência crítica e valores vinculados à cidadania se desenvolvam em seus alunos.

\section{A formação do professor de Artes na atualidade: globalização e pós-modernidade como desafios}

Um tema instigante e uma realidade desafiadora, que persiste na atualidade, é quanto à formação de docentes cuja função é o ensino de Arte para o ensino fundamental e médio no país.

Torna-se questionadora essa realidade no quadro educacional brasileiro, pois, muitas vezes, ou melhor, na maior parte das circunstâncias, profissionais sem formação de nível superior ocupam a função de docentes. Para a área de Artes, isso significa que os docentes da área têm carecido de uma formação básica, específica e, ao mesmo tempo, abrangente de Arte, seja ela nas áreas de música, dança, artes visuais ou teatro, como estão explicitadas no PCN de Artes (BRASIL, 1997).

Segundo Pereira (1999), desde a década de 1930, quando os cursos de licenciatura que habilitam professores para o exercício do magistério foram criados no Brasil, a proposta curricular de formação desses professores permanecia sem alterações 
significativas em seu modelo. A tramitação do anteprojeto que gerou a Lei de Diretrizes e Bases da Educação Nacional (BRASIL, 1996) suscitou, nos anos 1990, uma nova onda de debates sobre a formação docente no Brasil, em que participaram ativamente as entidades representantes de profissionais da educação e o mundo acadêmico. Assim, o novo modelo educacional a ser proposto foi amplamente discutido no Congresso Nacional, sobretudo, os novos parâmetros para a formação de professores que se tornavam evidentes com a Lei.

Na época em que a LDB foi aprovada, o contexto era marcado pela hegemonia das políticas neoliberais que estavam sendo implementadas na América Latina. $\bigcirc$ Fundo Monetário Internacional (FMI) e o Banco Mundial "procuravam promover a reforma do Estado, minimizando o seu papel", e favoreciam "o predomínio das regras do mercado em todos os setores da sociedade, incluindo as atividades educacionais" (PEREIRA, 1999).

Hoje, é notória a grande necessidade que temos da criação de cursos de licenciatura em todo o país, tendo em vista atender aos professores que atuam sem a formação mínima exigida pela Lei. O Plano Nacional de Educação (BRASIL, 2001) evidencia esta realidade. E no caso da disciplina Arte para a educação básica, a situação não é diferente.

À medida que o tempo passa nos temo-nos deparado com a necessidade dos docentes da área de se adaptarem às transformações que as condições impostas pelo capital trouxeram ao sistema educacional, que se apresenta como coadjuvante dos processos "evolutivos" do modelo econômico.

Refletir sobre a formação de professores de Arte torna-se imperativo para aqueles que se identificam com a área, levando em consideração as diferentes etapas da história do ensino artístico no país, às quais nos referimos nesse artigo: o início do século XX, quando o ensino era ministrado de forma a atender aos interesses de um Estado nacionalista e centralizador, e a atualidade, quando nos encontramos inseridos numa educação afetada pela globalização da economia e pela pós-modernidade.

A partir da implantação da política econômica neoliberal, transformações determinantes passaram a ocorrer no mundo e levaram as sociedades a se enquadrarem num sistema imposto pelos países que primeiro se industrializaram. Entendemos que esse processo alterou as funções de organização do Estado, e ao mesmo tempo, privou-o de investir como deveria em várias áreas da sociedade, entre elas, a educação.

Estado, sob o ponto de vista de Rummert $(2005$, p. 1) pode ser "compreendido como a forma de organização da dominação de uma classe sobre toda a sociedade, revestindo-se de grande complexidade." Esta classe, detentora do poder econômico, torna-se, no âmbito do Estado, "também em classe politicamente dominante", pois, segundo os seus interesses, tem influenciado na adoção dos parâmetros educacionais aos quais nos referimos.

Encontrar uma definição para a educação na pós-modernidade significaria, segundo Souza (2003, p. 15), enfrentar de modo crítico "as principais questões que 
regem os processos de subjetivação do mundo atual", bem como entender a cultura da nossa época, em que os sujeitos encontram-se constituídos em torno do consumo, do tempo livre e do prazer. O fato é que a nossa cultura tornou-se pós-moderna, regida e fragmentada pelo sistema imposto pelo capital, em que encontramos características que permeiam e se refletem na educação e nas Arte atuais.

Contudo, é oportuno lembrarmos uma pergunta feita por Franco (1999, p. 101): o "que significa preparar para o trabalho em um mundo como este"? E a partir disso, perguntamos: o que significa formar professores de Arte nos dias atuais? Como os cursos de licenciatura nas áreas de Arte têm encaminhado suas propostas curriculares para alunos que, por sua vez, serão formadores de cidadãos num futuro próximo? Com quais objetivos formam-se professores de Arte?

As mudanças trazidas pela globalização, e que afetam todas as áreas da esfera humana, contribuem para que as obras de Arte entrem nas escolas pelos museus virtuais, o que seria algo impossível sem o uso da tecnologia. Anteriormente à informatização nas escolas, esse recurso ainda não era realidade, e o acesso às obras, sobretudo às obras de arte que se encontram em museus, era bem menor. Não queremos afirmar, aqui, que as obras de arte perderam o seu fascínio devido ao acesso facilitado. Mas chamamos a atenção para o fato da facilidade do acesso permitir que grande parte de pessoas que, dificilmente buscariam admirá-las, estabeleçam um contato mais próximo com as obras de arte, especialmente na escola.

Esse acesso às artes visuais, que se tornou algo comum para a sociedade atual, também pode ser exemplificado por meio de telas de artistas famosos que se encontram impressas em capas de caderno, livros, revistas e disponíveis na internet, por exemplo. Concluímos que, devido às possibilidades permitidas pelos avanços da globalização e pelos aparatos tecnológicos, a análise e a percepção das produções visuais, bem como as diversas concepções estéticas, tornaram-se mais acessíveis e existem num sentido mais comum a todos.

As obras continuam sendo apreciadas nos museus, mas uma maneira de pensar que adentrou a identidade das culturas penetrou também todos os setores da sociedade, inclusive as escolas. Portanto, como conseqüência dos processos sociais da globalização, as culturas estão cada vez mais próximas umas das outras e o valor das artes visuais na vida dos indivíduos e seus significados expressivos colaboram para as possíveis articulações com o domínio estético-expressivo e o domínio ético na educação básica.

Deste modo, passa a haver a necessidade de os professores se adaptarem ao uso da tecnologia como um suporte necessário para as aulas de Arte, bem como ao uso de imagens e artistas que explorem temas sociais. Barbosa (2003) escreve referindo-se a críticos de Arte no Brasil que passaram a desprezar temas que artistas brasileiros exploravam e que denunciam realidades. Muitos desses artistas têm sido utilizados nas aulas de Arte, tal como Candido Portinari, por exemplo. Mas devido ao sistema globalizado que rege o mundo, alguns temas sociais não são postos em evidência, ficando escondidos. Segundo a autora, este fato também se estende na América Latina. 
Chegamos num ponto chave que pode tornar-se um dos fios condutores da discussão apresentada: o modo de vida do capitalismo tardio ou pós-industrial (JAMESON, 1996) tornou-se o grande responsável e a mola-mestra de todas as transformações que hoje permeiam a economia, a educação, a Arte, a cultura e o mundo do trabalho. O declínio de uma valorização da originalidade nas Artes deu lugar à suposição de que a Arte pode ser "arte" na repetição, e de que a genialidade do produtor artístico e o que ele deseja expressar não são mais valorizados. E, se não fosse somente isso, "é doloroso notar a perversidade destrutiva da intelectualidade em países de terceiro mundo" (BARBOSA, 2003, p. 113), que têm sido instrumento de desprezo por obras de Arte autênticas e expressivas.

Devemos ressaltar, como afirma Frigotto (1999, p. 26), que vivemos "sob a égide de uma sociedade classista, vale dizer, estruturada na extração de mais-valia absoluta, relativa e extra," em que as relações sociais são, por base, estabelecidas primeiramente por critérios materialistas. Educadores e educandos são agentes sociais que constituem essa contraditória trama de consciência crítica e de alienação, interagindo, assim, num processo educativo marcado pela lógica do mercado e por uma "noção de equivalência entre consumo e cidadania" (REIS; RODRIGUES, 2005, p. 2).

Precisamos entender e levar em consideração que a formação profissional atual, e aqui nos referimos à formação de professores, é vista como uma resposta estratégica, ou até mesmo uma conseqüência natural dos "problemas postos pela globalização econômica", gerados por uma busca da reestruturação produtiva, da qualidade e da competitividade, dando origem às transformações no mundo do trabalho (FRANCO, 1999, p. 101).

Se professores de Arte são agentes sociais, culturais e políticos, que promovem aos indivíduos a oportunidade de ampliar o entendimento para garantir a efetivação de uma cidadania ativa e participante (BRASIL, 1997), envolvendo as práticas artísticas, eles precisam abordar seus conteúdos e práticas de forma a levar seus alunos a refletirem na atualidade e em seus parâmetros.

É proposta do próprio $\mathrm{PCN}$ que os professores auxiliem seus alunos a posicionarse com sensibilidade e critérios éticos, diante de um conjunto de circunstâncias, pois trabalhar ética e estética na produção de Arte dos alunos e de artistas significa considerar suas possibilidades criadoras correlacionadas com as realidades socioculturais e comunicacionais em que vivem.

Já que é tarefa do poder público "a coordenação da política nacional de educação, articulando os diferentes níveis e sistemas e exercendo função normativa em relação às demais instâncias educacionais" (BRASIL, 1996), questionamos o seu papel, pois, diante de um mundo de culturas e saberes globalizados, tem deixado a desejar no que se refere ao investimento em políticas que priorizem a valorização dos professores de Arte, e que conceda a estes a possibilidade de obter subsídios para um investimento maior na formação de cidadãos na educação básica. 


\section{Referências}

ALMEIDA, C. Z. As relações arte/tecnologia no ensino da arte. In: PILLAR, A. D. (Org.). A educação do olhar no ensino das artes. Porto Alegre: Mediação, 2003.

BARBOSA, A. M. Arte: educação no Brasil. 3. ed. São Paulo: Perspectiva, 1999.

As escuelas de pintura al aire libre do México: liberdade, forma e cultura. In:

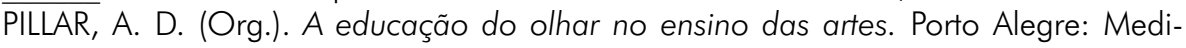
ação, 2003.

BRASIL. Câmara. Senado. Projeto de Lei n 2.732, de 21 de maio de 2008. Quero educação musical na escola, Rio de Janeiro, 2008. Disponível em: <http:// www.queroeducacaomusicalnaescola.com>. Acesso em: 11 jun. 2008.

. Lei $\mathrm{n}^{\circ}$. 4.024, de 20 de dezembro de 1961. Fixa as diretrizes e bases da educação nacional. Diário Oficial [da República Federativa do Brasil], Brasília, DF, 27 dez. 1961 e retificado em 28 dez. 1961.

. Lei $\mathrm{n}^{\circ}$ 5.692, de 11 de agosto de 1971. Fixa diretrizes e bases para o ensino de $1^{\circ}$ e $2^{\circ}$ graus, e dá outras providências. Leis, Brasília, DF, 1971. Disponível em: <http://www.planalto.gov.br>. Acesso em: 11 nov. 2008.

. Lei $n^{\circ}$ 9.394, de 20 de dezembro de 1996. Estabelece as diretrizes e bases da educação nacional. Diário Oficial [da República Federativa do Brasil], Brasília, DF, 23 dez. 1996. Seção 1, p. 27.839.

- Lei $n^{\circ}$ 10.172, de 9 de janeiro de 2001. Aprova o Plano Nacional de Educação e dá outras providências. PNE verso e reverso: Plano Nacional de Educação. Rio de Janeiro: Folha Dirigida, 2001.

. Ministério da Educação. Plano de Desenvolvimento da Educação. Brasília, DF, 2007. Disponível em: <http://www.mec.gov.br>. Acesso em: jun. 2008.

Ministério da Educação. Secretaria de Educação Fundamental. Parâmetros Curriculares Nacionais: arte. Brasília, DF: MEC, SEF, 1997.

FRANCO, M. C. Formação profissional para o trabalho incerto: um estudo comparativo Brasil, México e Itália. In: FRIGOTTO, G. (Org.). Educação e crise do trabaIho: perspectivas de final de século. 3. ed. Petrópolis, RJ: Vozes, 1999.

FRIGOTTO, G. Educação, crise do trabalho assalariado e do desenvolvimento: teorias em conflito. In: FRIGOTTO, G. (Org.). Educação e crise do trabalho: perspectivas de final de século. 3. ed. Petrópolis, RJ: Vozes, 1999.

FUSARI, M. F. R.; FERRAZ, M. H. C. T. Arte na educação escolar. São Paulo: Cortez, 2001. 
JAMESON, F. Pós-modernismo: a lógica cultural do capitalismo tardio. São Paulo: Ática, 1996.

JESUS, D. M. Educação inclusiva: uma proposta construída na/pela prática. Cadernos de Pesquisa em Educação, Vitória, ES, v. 8, n. 15, 2002.

MAGALHÃES, A. D. T. V. Ensino de arte: perspectivas com base na prática de ensino. In: BARBOSA, A. M. (Org.). Inquietações e mudanças no ensino da arte. São Paulo: Cortez, 2002.

MARQUES, C. A.; PEREIRA, J. E. D. Fóruns das licenciaturas em universidades brasileiras: construindo alternativas para a formação inicial de professores. Educação e Sociedade, Campinas, SP, v. 23, n. 78, p.117-142, abr. 2002. Disponível em: <http:/ /www.scielo.br >. Acesso em: jun. 2008

MEIRA, M. R. Educação estética, arte e cultura do cotidiano. In: PILLAR, A. D. (Org.). A educação do olhar no ensino das artes. Porto Alegre: Mediação, 2003.

PEREIRA, J. E. D. As licenciaturas e as novas políticas educacionais para a formação docente. Educação e Sociedade, Campinas, SP, v. 20, n. 68, dez. 1999. Disponível em: <http://www.scielo.br>. Acesso em: jun. 2008.

PIRES, M. C. M. Criação e cultura de massa. Uma relação possível? . In: SOUZA, S. J. (Org.). Educação @ pós-modernidade. Rio de Janeiro: 7 Letras, 2003.

REIS, R. R.; RODRIGUES, J. A universidade vai ao shopping center. Trabalho Necessário, Niterói, RJ, ano 3, n. 3, 2005. Disponível em: <www.uff.br/trabalhonecessario >. Acesso em: mar. 2008.

ROMANELLI, O. O. História da educação no Brasil. Petrópolis, RJ: Vozes, 1997.

RUMMERT, S. M. Entidades representativas dos interesses do trabalho: expressão da hegemonia do capital?. Trabalho Necessário, Niterói, RJ, ano 3, n. 3, 2005. Disponível em: <www.uff.br/trabalhonecessario>. Acesso em: mar. 2008.

SHIROMA, E. O.; MORAES, M. C. M.; EVANGELISTA, O. Política educacional. 2. ed. Rio de Janeiro: DP\&A, 2002.

SOUZA, S. J. Educação na pós-modernidade. Educar para quê?. In: SOUZA, S. J. (Org.).Educação @ pós-modernidade. Rio de Janeiro: 7 Letras, 2003.

Recebido em: 26/08/2008

Aceito para publicação em: 23/10/2008 